\title{
Article
}

\section{Cost-Effectiveness of Colorectal Cancer Genetic Testing}

\author{
Abdul Rahman Ramdzan ${ }^{1,2} \mathbb{D}$, Mohd Rizal Abdul Manaf $1, * \mathbb{D}$, Azimatun Noor Aizuddin ${ }^{1} \mathbb{D}$, Zarina A. Latiff ${ }^{3}$, \\ Keng Wee Teik ${ }^{4}$, Gaik-Siew Ch'ng ${ }^{4}$ (D), Kurubaran Ganasegeran ${ }^{5, *(D)}$ and Syed Mohamed Aljunid ${ }^{6}$ (D)
}

1 Department of Community Health, Faculty of Medicine, Universiti Kebangsaan Malaysia, Jalan Yaacob Latif, Bandar Tun Razak, Cheras, Kuala Lumpur 56000, Malaysia; abdul.rahman@ums.edu.my (A.R.R.); azimatunnoor@ppukm.ukm.edu.my (A.N.A.)

2 Department of Public Health Medicine, University of Malaysia Sabah, Jalan UMS, Kota Kinabalu 88400, Malaysia

3 Department of Paediatrics, Faculty of Medicine, Universiti Kebangsaan Malaysia, Jalan Yaacob Latif, Bandar Tun Razak, Cheras, Kuala Lumpur 56000, Malaysia; zarinaal@ppukm.ukm.edu.my

4 Genetic Department, Hospital Kuala Lumpur, Jalan Pahang, Kuala Lumpur 50586, Malaysia; wtkeng@moh.gov.my (K.W.T.); gaiksiew@moh.gov.my (G.-S.C.)

5 Clinical Research Center, Seberang Jaya Hospital, Ministry of Health Malaysia, Penang 13700, Malaysia

6 Department of Health Policy and Management, Kuwait University, 320 St, Hawally 13110, Kuwait; syed.aljunid@hsc.edu.kw

* Correspondence: mrizal@ppukm.ukm.edu.my (M.R.A.M.); medkuru@yahoo.com (K.G.)

\section{check for} updates

Citation: Ramdzan, A.R.; Manaf, M.R.A.; Aizuddin, A.N.; Latiff, Z.A.; Teik, K.W.; Ch'ng, G.-S.; Ganasegeran, K.; Aljunid, S.M. Cost-Effectiveness of Colorectal Cancer Genetic Testing. Int J. Environ. Res. Public Health 2021, 18 , 8330. https://doi.org/10.3390/ ijerph18168330

\section{Academic Editors:}

Vincenza Gianfredi and Paul

B. Tchounwou

Received: 30 June 2021

Accepted: 3 August 2021

Published: 6 August 2021

Publisher's Note: MDPI stays neutral with regard to jurisdictional claims in published maps and institutional affiliations.

Copyright: (c) 2021 by the authors Licensee MDPI, Basel, Switzerland. This article is an open access article distributed under the terms and conditions of the Creative Commons Attribution (CC BY) license (https:// creativecommons.org/licenses/by/ $4.0 /)$.

\begin{abstract}
Colorectal cancer (CRC) remains the second leading cause of cancer-related deaths worldwide. Approximately 3-5\% of CRCs are associated with hereditary cancer syndromes. Individuals who harbor germline mutations are at an increased risk of developing early onset CRC, as well as extracolonic tumors. Genetic testing can identify genes that cause these syndromes. Early detection could facilitate the initiation of targeted prevention strategies and surveillance for CRC patients and their families. The aim of this study was to determine the cost-effectiveness of CRC genetic testing. We utilized a cross-sectional design to determine the cost-effectiveness of CRC genetic testing as compared to the usual screening method (iFOBT) from the provider's perspective. Data on costs and health-related quality of life (HRQoL) of $200 \mathrm{CRC}$ patients from three specialist general hospitals were collected. A mixed-methods approach of activity-based costing, top-down costing, and extracted information from a clinical pathway was used to estimate provider costs. Patients and family members' HRQoL were measured using the EQ-5D-5L questionnaire. Data from the Malaysian Study on Cancer Survival (MySCan) were used to calculate patient survival. Cost-effectiveness was measured as cost per life-year (LY) and cost per quality-adjusted life-year (QALY). The provider cost for CRC genetic testing was high as compared to that for the current screening method. The current practice for screening is cost-saving as compared to genetic testing. Using a 10-year survival analysis, the estimated number of LYs gained for CRC patients through genetic testing was 0.92 years, and the number of QALYs gained was 1.53 years. The cost per LY gained and cost per QALY gained were calculated. The incremental cost-effectiveness ratio (ICER) showed that genetic testing dominates iFOBT testing. CRC genetic testing is cost-effective and could be considered as routine CRC screening for clinical practice.
\end{abstract}

Keywords: colorectal cancer; genetic testing; cost-effectiveness; quality of life; economic evaluation

\section{Introduction}

Colorectal cancer (CRC) has been reported as the third most commonly diagnosed cancer after lung and breast cancers [1] and the second leading cause of cancer mortality after lung malignancy worldwide [2-4]. In Malaysia, approximately 3000 new CRC cases are reported annually [5], constituting the second largest cancer incidence rate after breast malignancy and the third leading cause of cancer deaths. While the annual global incidence and mortality rates of CRCs comprise approximately one million cases and around 
600,000 deaths, respectively, the bulk of these diagnosed cases from large surveillance systems or registry data are of hereditary and familial CRCs [6-8].

As it is a genetically related cancer, genetic testing is one useful tool for screening the risk of cancer inheritance among family members of CRC patients [9-14]. Mutations in the MLH1, MSH2, MSH6, and PMS2 genes increase the risk for developing CRCs, especially in Lynch syndrome [15-22].

As the global burden of CRCs is expected to be commensurate with population aging, the costs of cancer treatments are projected to escalate simultaneously [23-32]. CRC treatment costs and expenditures can be reduced significantly if screening efforts are carried out early, actively, and rigorously [33,34]. Studies in the literature have highlighted that the probability of survival is greater among CRC patients in developed nations due to advancement of screening capacities, detection, and treatment modalities [35-38].

Although several conventional screening methods are available for CRC detection [39-41], there is a need to explore newer interventions with better diagnostic accuracy and performance to conduct early risk assessments for populations susceptible to hereditary CRCs. The current available interventions in Malaysia include the immunological-based fecal occult blood test (iFOBT) and the colonoscopy test for at-risk populations aged 50 years and above [42]. According to the Malaysian Clinical Practice Guidelines for Colorectal Cancer, medium- and high-risk groups are referred to colonoscopy, while CRC genetic testing is optional [43]. Genetic testing in Malaysia is still a less widely used and underutilized screening mode for CRCs [43]. As perceived susceptibility to CRC is attributable to family history in younger age groups [44], it is timely to expand CRC genetic testing capacities as a routine mode for screening in the effort to detect CRCs early, especially in the younger population with a family history of cancer. However, to adopt newer interventions for practice, it is crucial to convince stakeholders and policy makers on the costs and effectiveness of such interventions. The need for effective use of scarce resources has been consistently extended to all aspects of medicine and public health practice. Clinicians and public health advocates have always been concerned with prudent use of resources, and they make careful decisions that take into account both the effectiveness and the costs of the interventions or treatment involved.

Economic evaluation is important to ensure optimal use of the available resources to achieve the desired results. With limited resources in the healthcare system, costeffectiveness analysis is a useful tool to assess cost-outcome relationships prior to introducing newer, compatible, and more effective interventions. CRC genetic testing is an alternative to the current screening methods for detecting CRC at an early stage. Research on the cost-effectiveness of CRC genetic testing is a key step to obtain accurate and complete information before policy makers decide to expand its use nationally [45].

Studies that conducted cost-effectiveness analysis of CRC genetic testing [46-51] concluded that genetic testing is cost-effective in the detection of colorectal malignancy. To the best of our knowledge, there have been no studies of cost-effectiveness related to CRC genetic testing conducted in Malaysia to date. Underlying the premise of healthcare resource scarcity in the quest to maximize health gains for CRC susceptibles and survivors in Malaysia, the aim of this economic evaluation is to determine the cost-effectiveness of CRC genetic testing from the perspective of healthcare providers in Malaysia.

\section{Materials and Methods}

\subsection{Study Design and Setting}

A cross-sectional study was conducted among CRC patients at three tertiary hospitals in Malaysia from September 2018 until November 2019.

\subsection{Study Participants}

Study participants were recruited via convenience sample based on the sampling frame of name lists of CRC patients who underwent either iFOBT screening tests or genetic testing at the relevant hospitals. Malaysian adults aged 18 to 85 years of age who were able to read and converse in English or Malay were recruited. Participants deemed physically 
or mentally unfit to be administered a questionnaire were excluded. Written consents were obtained from those who agreed to participate. A validated questionnaire was used for data collection, consisting of socio-demographic characteristics, health-related quality of life (HRQoL), and resource utilization forms.

\subsection{Study Perspective, Instruments, and Resources Used}

A cost-effectiveness analysis of CRC genetic testing was conducted relative to its comparator, the iFOBT, from the healthcare providers' perspective in Malaysia, particularly for the Ministry of Health Malaysia as a supplier's perspective across specialist referral hospitals. Resource utilization forms were used to obtain information related to the costs of the intervention and treatment, while a self-administered questionnaire was used to collect the demographic information of the participants and HRQoL measured as a utility score.

\subsection{Outcomes}

To determine the effectiveness of a new intervention, the HRQoL of CRC patients was measured using a validated EuroQol instrument, the EQ-5D-5L scale. This tool is often used to determine utility in terms of quality-adjusted life-years (QALYs) during health economic evaluations [52,53]. The Malaysian version of the EQ-5D-5L has been previously validated and adopted for use in the Malaysian healthcare setting [54-56]. The EQ-5D-5L valuation for the Malaysian population was used [55].

The EQ-5D-5L is a multi-attribute utility scale (MAUS) that contains a set of questions used to obtain a self-description of current HRQoL across five domains (an EQ-5D descriptive system) and a rating on a visual analog scale (VAS). The five dimensions of the EQ-5D are mobility, self-care, usual activities, pain or discomfort, and anxiety or depression; these are used as a health profile and converted to an index score to describe the utility value for the current health state. For the VAS rating scale, participants are required to rate their health status in a scale of 0-100, in which a higher rating indicates better HRQoL [53]. Participants should mark on the scale to describe their current health status [57].

Life-years (LYs) gained for CRC patients were estimated by multiplying the mean survival time according to the stage of CRC (according to the Malaysia Study on Cancer Survival report) by the number of patients undergoing genetic testing or the iFOBT [58]. Meanwhile, the QALYs for CRC patients were estimated by multiplying the LYs with the mean utility score according to the stage of cancer. The years of life gained by patients who underwent CRC genetic testing were calculated by obtaining the difference between the LYs of patients who underwent genetic testing and the LYs of patients who underwent the iFOBT.

\subsection{Estimating Resources Used and Cost Analysis}

In this study, we adopted single-study-based economic evaluation. The types of costs used in this study were capital and recurrent costs. Capital costs consist of building costs and equipment costs. Recurrent costs consist of human resource costs, administration or overhead costs, utility costs, maintenance costs, medication costs, consumables, and laboratory investigation costs. The cost analysis method adopted in this study was based on those in previous studies $[59,60]$. The method was based on cost analysis guidelines in primary health care and methods for economic evaluation for healthcare programs [61,62]. All cost data were collected from 1 July 2018 to 28 February 2019 via central costs and resource utilization forms.

Two costing methods were used in this study, namely, the top-down costing method and the activity-based costing method formulated through a clinical pathway. The topdown costing method starts with the total expenditure divided by the total number of patients undergoing genetic testing and the iFOBT, then multiplied by the average number of visits to obtain the average cost per patient per visit. Meanwhile the activity-based costing method is a method that allocates costs to products and services by assigning costs to all activities used directly for undergoing CRC screening. 


\subsection{Cost-Effectiveness Analysis}

Cost-effectiveness analysis was performed based on the costs, utility scores, and mean survival time. The cost-effectiveness in this study is presented as cost per LY gained and cost per QALY computed. It was calculated as cost/effectiveness (LY/QALY). The incremental cost-effectiveness ratio (ICER) was calculated as the cost-effectiveness of genetic testing minus the cost-effectiveness of the iFOBT.

\subsection{Assumptions and Analytical Choice}

In the current study, we adopted cost-effectiveness analysis for diagnostic testing as compared to conventional health economic evaluations that apply such approaches to either new interventions or treatment modalities. Such economic evaluations require the value of diagnostics to be established and integrated with prognostics of health status [63], which explicitly requires the diagnostic accuracy and performance values of new assessments to be synthesized in comparison to conventional tools to warrant an economic evaluation analysis to support policy decisions. In this study, we adopted diagnostic performance values based on a recent systematic review of accuracy in CRC genetic testing [64]. The pooled estimates for sensitivity and specificity were $71 \%$ (95\% CI 66, 75\%) and 95\% (95\% CI: 93, 97\%), respectively. Relative to the accuracy of the iFOBT, the pooled estimated sensitivity was $31 \%$ (95\% CI: $25,38 \%$ ), while the pooled specificity was $87 \%$ (95\% CI: $86,89 \%$ ). These values suggest that genetic testing can detect CRC better at an early stage, promising better health outcomes. The outcome of these performance values forms the basis of the current economic evaluation of genetic testing and justification that it is worthwhile. As a decision tree for an economic model could not be established in view of resource and data scarcity on CRC genetic testing in Malaysia, we required strong assumptions to support the execution of cost-effectiveness analysis of CRC genetic testing. The assumptions made in this study include the following:

I. A better screening method is able to detect CRC at an early stage;

II. The earlier the stage at which CRC is diagnosed, the better the QALY gain;

III. Samples in both screening groups had been tested positive and confirmed to have CRC;

IV. Total cost management includes the costs of screening and treatment.

\subsection{Currency, Price Date, and Conversion}

All unit costs were adjusted to financial year 2019 using Malaysia consumer price indexes. These costs were then converted into U.S. Dollars using the exchange rate for 2019 (1 USD to $4.14 \mathrm{RM}$ ).

\subsection{Data Analysis}

Descriptive and inferential statistics were employed to explore sample characteristics, HRQoL, and the cost of CRC screening methods. The results for continuous variables are presented as means and standard deviations (SDs), and medians. For categorical data, the results are presented as frequencies and relative frequencies (\%). Where inferences were made, non-parametric Mann-Whitney U, Kruskal-Wallis, and Chi-Square tests were conducted. Statistical significance was set at $p<0.05$. Cost analysis and cost-effectiveness analysis for CRC genetic testing was performed. The resulting ICER is graphically presented in a cost-effectiveness (CE) plane.

Variation in costs (mean difference and 95\% confidence intervals) yielded through one-sample t-testing is reported to handle stochastic uncertainty. To handle deterministic uncertainty, sensitivity analysis was performed based on the principle of cost reduction. This was done by changing the discount rate from $3 \%$ to $5 \%$, in addition to the base case, and was applied to both costs and consequences of the tests. All data were analyzed using SPSS Software version 27.0 (IBM, Armonk, NY, USA). 


\section{Results}

\subsection{Sample Characteristics}

Table 1 shows the sample characteristics. Of the 200 CRC patients recruited, 100 $(50.0 \%)$ had an iFOBT, while $100(50.0 \%)$ underwent genetic testing. A majority of the CRC patients were men (55\%) and aged $\leq 50$ years old $(36 \%)$. Most patients were Malays $(70.0 \%)$, married $(78.5 \%)$, and had a secondary education $(58.5 \%)$. The bulk of the patients were working $(72.5 \%)$ with a monthly household income in the range 1500-3500 RM (46.5\%). The mean (SD) age of CRC patients was 52.9 (15.8) years. The mean (SD) age of patients who had an iFOBT was 54.9 (15.3) years, while the mean (SD) age of patients who underwent genetic testing was 47.2 (16.2) years.

Table 1. Sample characteristics $(n=200)$.

\begin{tabular}{|c|c|c|c|c|}
\hline Characteristics & $\begin{array}{c}\text { Total Patients } \\
n(\%)\end{array}$ & $\begin{array}{c}\text { iFOBT } \\
n(\%)\end{array}$ & $\begin{array}{c}\text { Genetic Testing } \\
n(\%)\end{array}$ & $p$-Value \\
\hline Age in years, mean (SD) & $52.9(15.8)$ & $54.9(15.3)$ & $47.2(16.2)$ & $0.159^{a}$ \\
\hline Age group in years & & & & $0.009^{\mathrm{b}}$ \\
\hline$\leq 50$ & $72(36.0)$ & $30(30.0)$ & $42(42.0)$ & \\
\hline $51-60$ & $49(24.5)$ & $28(28.0)$ & $21(21.0)$ & \\
\hline $61-70$ & $59(29.5)$ & $31(31.0)$ & $28(28.0)$ & \\
\hline$\geq 71$ & $20(10.0)$ & $11(11.0)$ & $9(9.0)$ & \\
\hline Gender & & & & $0.235^{\mathrm{a}}$ \\
\hline Men & $110(55.0)$ & $57(57.0)$ & $53(53.0)$ & \\
\hline Women & $90(45.0)$ & $43(43.0)$ & $47(47.0)$ & \\
\hline Ethnicity & & & & $0.113^{b}$ \\
\hline Malay & $140(70.0)$ & $73(73.0)$ & $67(67.0)$ & \\
\hline Chinese & $38(19.0)$ & $15(15.0)$ & $23(23.0)$ & \\
\hline Indian & $22(11.0)$ & $12(12.0)$ & $10(10.0)$ & \\
\hline Current working status & & & & $<0.001^{a}$ \\
\hline Yes & $145(72.5)$ & $91(91.0)$ & $54(54.0)$ & \\
\hline No & $55(27.5)$ & $9(9.0)$ & $46(46.0)$ & \\
\hline Monthly household income (RM) * & & & & $0.036^{\mathrm{b}}$ \\
\hline$<1500$ & $77(38.5)$ & $41(41.0)$ & $36(36.0)$ & \\
\hline $1500-3500$ & $93(46.5)$ & $41(41.0)$ & $52(52.0)$ & \\
\hline$>3500$ & $30(15.0)$ & $18(18.0)$ & $12(12.0)$ & \\
\hline Education level & & & & $<0.001^{b}$ \\
\hline No education & $17(8.5)$ & $6(6.0)$ & $11(11.0)$ & \\
\hline Primary & $30(15.0)$ & $11(11.0)$ & $19(19.0)$ & \\
\hline Secondary & $117(58.5)$ & $68(68.0)$ & $49(49.0)$ & \\
\hline Tertiary & $36(18.0)$ & $15(15.0)$ & $21(21.0)$ & \\
\hline Marital status & & & & $0.043^{\mathrm{a}}$ \\
\hline Single & $43(21.5)$ & $18(18.0)$ & $25(25.0)$ & \\
\hline Married & $157(78.5)$ & $82(82.0)$ & $75(75.0)$ & \\
\hline Insurance coverage & & & & $0.629^{a}$ \\
\hline Yes & $28(14.0)$ & $15(15.0)$ & $13(13.0)$ & \\
\hline No & $172(86.0)$ & $85(85.0)$ & $87(87.0)$ & \\
\hline Family history of cancer & & & & $<0.001^{a}$ \\
\hline Yes & $111(55.5)$ & $40(40.0)$ & $71(71.0)$ & \\
\hline No & $89(44.5)$ & $60(60.0)$ & $29(29.0)$ & \\
\hline
\end{tabular}


Table 1. Cont.

\begin{tabular}{cccc}
\hline Characteristics & $\begin{array}{c}\text { Total Patients } \\
\boldsymbol{n} \mathbf{( \% )}\end{array}$ & $\begin{array}{c}\text { iFOBT } \\
\boldsymbol{n} \mathbf{( \% )}\end{array}$ & $\begin{array}{c}\text { Genetic Testing } \\
\boldsymbol{n} \mathbf{( \% )}\end{array}$ \\
\hline Stage of cancer & & & $10(10.0)$ \\
1 & $16(8.0)$ & $6(6.0)$ & $60(60.0)$ \\
2 & $77(38.5)$ & $17(17.0)$ & $25(25.5)$ \\
4 & $79(39.5)$ & $54(54.0)$ & $5(5.0)$ \\
\hline Treatment & $28(14.0)$ & $23(23.0)$ & $99(99.0)$ \\
Surgery & & & $13(13.0)$ \\
Radiotherapy & $199(99.5)$ & $100(100.0)$ & $69(69.0)$ \\
\hline
\end{tabular}

${ }^{\text {a }}$ Mann-Whitney U test; ${ }^{\mathrm{b}}$ Kruskal-Wallis test; ${ }^{*} 1$ USD equals RM 4.14 at the time of study; iFOBT: immunological-based fecal occult blood test; SD: standard deviation.

\subsection{Cost Analysis}

The cost for one patient who had an iFOBT or genetic testing in a year was estimated using the top-down and activity-based costing methods. The total cost for one patient who had an iFOBT in a year was USD 372.83, while the total cost for one patient who underwent genetic testing was USD 976.26 (Table 2).

Table 2. Cost analysis of the iFOBT and CRC genetic testing (USD).

\begin{tabular}{|c|c|c|c|c|}
\hline Type of Cost & Costing Methods & $\begin{array}{c}\text { iFOBT } \\
\text { Mean (SE) }\end{array}$ & $\begin{array}{c}\text { Genetic Testing } \\
\text { Mean (SE) }\end{array}$ & $\begin{array}{c}\text { Difference } \\
\text { Mean }(95 \% \text { CI) }\end{array}$ \\
\hline \multicolumn{5}{|l|}{ Capital cost (USD) } \\
\hline Building & Top-down & $62.48(0.09)$ & $59.93(0.03)$ & $2.568(2.565-2.571)$ \\
\hline Equipment & Top-down & $8.58(0.01)$ & $8.29(0.05)$ & $0.300(0.298-0.303)$ \\
\hline \multicolumn{5}{|l|}{ Recurrent cost (USD) } \\
\hline Human resource & Activity-based & $43.23(0.48)$ & $56.96(0.02)$ & 13.789 (13.771-13.808) \\
\hline Administration/overhead & Top-down & $118.13(0.47)$ & $174.85(0.10)$ & $56.329(56.238-56.421)$ \\
\hline Utilities & Top-down & $69.59(0.98)$ & $66.75(0.05)$ & $2.787(2.770-2.803)$ \\
\hline Maintenance & Top-down & $4.33(0.06)$ & $4.15(0.03)$ & $0.183(0.180-0.185)$ \\
\hline Medication & Activity-based & $19.45(0.66)$ & $0.74(0.12)$ & $18.751(18.741-18.760)$ \\
\hline Consumables & Activity-based & $1.15(0.01)$ & $0.73(0.09)$ & $0.407(0.404-0.409)$ \\
\hline Laboratory investigation & Activity-based & $45.89(0.05)$ & $603.86(0.06)$ & $557.940(557.931-557.949)$ \\
\hline Total cost (USD) & & $372.83(0.09)$ & $976.26(0.07)$ & $603.424(603.422-603.425)$ \\
\hline
\end{tabular}

SE: standard error; USD: United States Dollar.

\subsection{Outcomes}

Table 3 shows the proportions of patient-reported problems among those who underwent the iFOBT or genetic testing in each dimension of the EQ-5D-5L. The problem least reported amongst patients who underwent iFOBT or genetic testing was regarding self-care $(29.9 \%$ vs. $31.0 \%, p=0.869)$. The highest reported problem was pain or discomfort among patients who underwent the iFOBT or genetic testing, and the difference was statistically significant $(43.3 \%$ vs. $74.1 \%, p<0.001)$. The overall mean (SD) utility score for all patients was 0.787 (0.273). The mean (SD) utility score for patients who underwent an iFOBT was 0.801 (0.264), while the mean (SD) utility score for patients who underwent genetic testing was 0.744 (0.296). On the rating scale, the mean (SD) VAS score was 73.58 (18.47) for the overall sample, while the mean (SD) VAS scores for patients who underwent the iFOBT and genetic resting were 73.10 (17.28) and 74.93 (21.29), respectively. There were no statistical differences between patients who underwent the iFOBT and those who underwent genetic testing in terms of utility or VAS score (Table 3). Spearman's correlation was used to determine the relationship between the utility score and the VAS score. There was a strong 
positive correlation with statistical significance between the utility score and the VAS score $(\mathrm{r}=0.742, p<0.001)$.

Table 3. Proportions of problems reported in the EQ-5D-5L dimensions and the patients' utility and VAS scores $(n=200)$.

\begin{tabular}{|c|c|c|c|c|}
\hline Attribute & $\begin{array}{c}\text { Total Patients } \\
n(\%)\end{array}$ & $\begin{array}{l}\text { iFOBT } \\
n(\%)\end{array}$ & $\begin{array}{c}\text { Genetic Testing } \\
n(\%)\end{array}$ & $p$-Value \\
\hline Mobility & $83(37.4)$ & $60(36.6)$ & $23(39.7)$ & $0.678^{a}$ \\
\hline Self-care & $67(30.2)$ & $49(29.9)$ & $18(31.0)$ & $0.869^{\mathrm{a}}$ \\
\hline Usual activities & $86(38.7)$ & $67(40.9)$ & $19(32.8)$ & $0.277^{\mathrm{a}}$ \\
\hline Pain or discomfort & $114(51.4)$ & $71(43.3)$ & $43(74.1)$ & $<0.001^{\mathrm{a}}$ \\
\hline Anxiety or depression & $98(44.1)$ & $70(42.7)$ & $28(48.3)$ & $0.461^{\mathrm{a}}$ \\
\hline Utility score, mean (SD)/median & $0.787(0.273) / 0.861$ & $0.801(0.264) / 0.890$ & $0.744(0.296) / 0.834$ & $0.121^{b}$ \\
\hline VAS score, mean (SD)/median & $73.58(18.47) / 78.20$ & $73.10(17.28) / 77.50$ & $74.93(21.59) / 80.00$ & $0.288^{b}$ \\
\hline
\end{tabular}

${ }^{\mathrm{a}}$ Chi-square test $\left(\chi^{2}\right) ;{ }^{\mathrm{b}}$ Mann-Whitney U test.

\subsection{Life-Years ( $L Y S)$ and Quality-Adjusted Life-Years (QALYS)}

The numbers of life-years (LYs) for patients according to cancer stage were 5.21 years for patients who underwent the iFOBT and 6.13 years for patients who underwent genetic testing. The number of quality-adjusted life-years (QALYs) for patients who underwent the iFOBT according to cancer stage was 3.44 years, while the number of QALYs for patients who underwent genetic testing was 4.97 years. The mean survival times for patients who underwent the iFOBT and genetic testing are illustrated in Table 4.

Table 4. Mean survival times for patients who underwent the iFOBT and genetic testing.

\begin{tabular}{|c|c|c|c|c|c|}
\hline Stage & Mean Survival Time & $n$ & Total (Years) & Mean Utility Score & QALYs \\
\hline \multicolumn{6}{|l|}{ iFOBT } \\
\hline I & 6.71 & 6 & 40.26 & 0.87 & 35.03 \\
\hline II & 6.51 & 17 & 110.67 & 0.74 & 81.90 \\
\hline III & 5.65 & 54 & 305.1 & 0.72 & 219.67 \\
\hline IV & 2.84 & 23 & 65.32 & 0.11 & 7.19 \\
\hline Total & & 100 & 521.35 & & 343.78 \\
\hline Per patient & & & 5.21 & & 3.44 \\
\hline \multicolumn{6}{|l|}{ Genetic testing } \\
\hline I & 6.71 & 10 & 67.1 & 0.85 & 57.04 \\
\hline II & 6.51 & 60 & 390.60 & 0.82 & 320.29 \\
\hline III & 5.65 & 25 & 141.25 & 0.77 & 108.76 \\
\hline IV & 2.84 & 5 & 14.20 & 0.75 & 10.65 \\
\hline Total & & 100 & 613.15 & & 496.74 \\
\hline Per patient & & & 6.13 & & 4.97 \\
\hline
\end{tabular}

QALYs: Quality-Adjusted Life-Years; iFOBT: immunological-based fecal occult blood test; Stage I, II, III \& IV: stage of colorectal cancer.

\subsection{Life-Years (LYS) and Quality-Adjusted Life-Years (QALYs) Gained by Patients Who Underwent Genetic Testing}

The number of years of life gained by patients who underwent CRC genetic testing was calculated by obtaining the difference between the LYs of patients who underwent genetic testing (6.13 years) and the LYs of patients who underwent the iFOBT (5.21 years). The number of LYs gained by CRC patients who underwent genetic testing was 0.92 years. The number of QALYs gained for CRC patients who underwent genetic testing was calculated by obtaining the difference between the QALYs of patients who underwent genetic testing (4.97 years) and the QALYs of patients who underwent the iFOBT (3.44 years). The number of QALYs gained by CRC patients through genetic testing was 1.53 years (Table 5 ). 
Table 5. Cost-effectiveness analysis of genetic testing.

\begin{tabular}{ccc}
\hline Item & iFOBT & Genetic Testing \\
\hline LYs gained & 5.21 & 6.13 \\
QALYs gained & 3.44 & 4.97 \\
Provider cost (USD) & 372.83 & 976.26 \\
Cost per LY (USD) & 71.56 & 159.26 \\
Cost per QALY (USD) & 108.38 & 196.43 \\
\hline
\end{tabular}

iFOBT: immunological-based fecal occult blood test; LYs: Life-Years; QALYs: Quality-Adjusted Life-Years; USD: United States Dollar.

\subsection{Cost-Effectiveness Analysis}

Table 5 shows the cost and effectiveness values, i.e., LYs and QALYs gained for the iFOBT and genetic testing in base case analysis. The number of LYs gained by patients who underwent genetic testing was higher (6.13 years) as compared to that by patients who underwent the iFOBT (5.21 years). A gain of approximately 4.97 QALYs was observed for patients who underwent genetic testing, as compared to 3.44 QALYs gained for patients who underwent the iFOBT. The provider cost for patients who underwent genetic testing was USD 976.26, approximately USD 603.43 higher than the provider cost for patients who underwent an iFOBT (USD 372.83).

The cost per LY for patients who underwent genetic testing was USD 159.26, which was USD 87.70 higher than the cost per LY for patients who underwent an iFOBT (USD 71.56). The cost per QALY for patients who underwent genetic testing was USD 196.43, which was USD 88.05 higher than the cost per QALY for patients who underwent the iFOBT (USD 108.38). The cost ratios per LY and per QALY were 2.23 and 1.81, respectively, for patients who underwent genetic testing compared to those who underwent the iFOBT.

The costs and outcomes of intervention with similar objectives would be better when compared at the group level rather than the individual level, especially when the outcomes differ by scales or scores. By grouping patients, the QoL scores of CRC patients with different characteristics were considered. In reality, each health intervention that is under consideration for a policy implementation in society should be carried out as a whole. Table 6 exhibits the QALYs gained and testing costs per 100 patients. Following these results, the incremental cost-effectiveness ratio (ICER) was calculated. The ICER was computed based on the difference in the total cost of management for CRC patients between the two test groups divided by the QALY difference between the two test groups. The cost of managing CRC includes the cost of screening and the cost of treatment. QALYs, on the other hand, are the life-years gained (years of survival) multiplied by the quality-of-life score (QoL) once diagnosed with cancer. The information required is the cost of treatment at each stage of CRC, the number of patients at each stage of CRC in both groups, and the QALYs for each stage of CRC (Table 7).

Based on Table 6, it was found that the number of QALYs decreased as the stage of cancer increased. The percentages of early stage I and II CRCs were $70 \%$ for genetic testing and $23 \%$ for the iFOBT. This means that CRC is found earlier through genetic testing as compared to the iFOBT. Based on the results from Table 7, it was found that the cost of managing CRC patients rose in line with the increased cancer levels. The cost of genetic testing was more than double the cost of the iFOBT.

Therefore, the incremental cost-effectiveness ratio (ICER) was calculated as follows:

$\frac{\text { Total cost managing CRC patients screened by GT (USD) - Total cost managing CRC patients screened by iFOBT (USD) }}{\text { Total QALY for patients screened by GT }(n=100) \text {-Total QALY for patients screened by iFOBT }(n=100)}=$ ICER

$$
\frac{\mathrm{USD} 600,651.33-\mathrm{USD} 615,948.66}{496.74-343.78}=\frac{-\mathrm{USD} 15,297.33}{152.96}=-\mathrm{USD} 100.01 \text { (Genetic testing dominates) }
$$


Table 6. Quality-adjusted life-years (QALYs) gained.

\begin{tabular}{|c|c|c|c|c|c|c|c|c|c|}
\hline \multirow{2}{*}{$\begin{array}{l}\text { Stage of } \\
\text { Cancer }\end{array}$} & \multirow{2}{*}{$\begin{array}{l}\text { Life-Years } \\
\text { (LY) }\end{array}$} & \multicolumn{4}{|c|}{ iFOBT } & \multicolumn{4}{|c|}{ Genetic Testing } \\
\hline & & QoL & QALYs & $n$ & $\begin{array}{c}\text { QALYs (per } \\
100 \text { Patients) }\end{array}$ & QoL & QALYs & $n$ & $\begin{array}{l}\text { QALYs (per } \\
100 \text { Patients) }\end{array}$ \\
\hline I & 6.71 & 0.87 & 5.84 & 6 & 35.03 & 0.85 & 5.70 & 10 & 57.04 \\
\hline II & 6.51 & 0.74 & 4.82 & 17 & 81.90 & 0.82 & 5.34 & 60 & 320.29 \\
\hline III & 5.65 & 0.72 & 4.07 & 54 & 219.67 & 0.77 & 4.35 & 25 & 108.76 \\
\hline IV & 2.84 & 0.11 & 0.31 & 23 & 7.19 & 0.75 & 2.13 & 5 & 10.65 \\
\hline \multicolumn{3}{|c|}{ Total QALY gain } & & \multirow{2}{*}{\multicolumn{2}{|c|}{$\begin{array}{r}343.78 \\
\text { USD } 37283.53\end{array}$}} & & & \multirow{2}{*}{\multicolumn{2}{|c|}{$\begin{array}{r}496.74 \\
\text { USD 97.626.33 }\end{array}$}} \\
\hline \multicolumn{3}{|c|}{ Screening cost (per 100 patients) } & & & USD 37,283.53 & & & & \\
\hline
\end{tabular}

iFOBT: immunological-based fecal occult blood test; LYs: Life-Years; QALYs: Quality-Adjusted Life-Years; USD: United States Dollar.

Table 7. Cost of managing colorectal cancer patients.

\begin{tabular}{|c|c|c|c|c|c|}
\hline \multirow{2}{*}{ Stage of Cancer } & \multirow{2}{*}{$\begin{array}{l}\text { Treatment [27] } \\
\text { Cost (USD) }\end{array}$} & \multicolumn{2}{|c|}{ iFOBT } & \multicolumn{2}{|c|}{ Genetic Testing } \\
\hline & & $n$ & Cost (USD) & $n$ & Cost (USD) \\
\hline $\mathrm{I}$ & $3,290.34$ & 6 & $19,742.04$ & 10 & $32,903.40$ \\
\hline II & $4,771.01$ & 17 & $81,107.17$ & 60 & $286,260.60$ \\
\hline III & 6031.88 & 54 & $325,721.52$ & 25 & 150797.00 \\
\hline IV & 6612.80 & 23 & $152,094.40$ & 5 & $33,064.00$ \\
\hline \multicolumn{2}{|c|}{ Total treatment cost } & \multicolumn{2}{|r|}{$578,665.13$} & & $503,025.00$ \\
\hline \multicolumn{2}{|c|}{ Screening cost (per 100 patients) } & \multicolumn{2}{|r|}{$37,283.53$} & & $97,626.33$ \\
\hline \multicolumn{2}{|c|}{ Total cost of managing CRC patients } & \multicolumn{2}{|r|}{$615,948.66$} & & $600,651.33$ \\
\hline
\end{tabular}

iFOBT: immunological-based fecal occult blood test; USD: United States Dollar; CRC: colorectal cancer.

Based on the ICER calculations, it was found that genetic testing dominates iFOBT testing when considering the total cost of managing CRC patients and the QALYs gained as the effectiveness. Figure 1 exhibits a cost-effectiveness plane for CRC genetic testing compared to iFOBT testing. The figure shows that the ICER fell in the southeast quadrant, confirming that genetic testing has good value for money (dominant), and decision makers should consider investing in and expanding the use of genetic testing in routine CRC screening for clinical practice.

\subsection{Sensitivity Analysis}

In this study, a one-way sample sensitivity analysis was performed by varying the discount rates from $3 \%$ to $5 \%$, in addition to the base case, with the cost and yielded values reported in each sample. The sensitivity analysis results are summarized in Table 8.

Table 8. Sensitivity analysis for the cost-effectiveness of genetic testing versus iFOBT.

\begin{tabular}{cccc}
\hline Item & Base Case & Discount 3\% & Discount 5\% \\
\hline iFOBT & & & $354.19(0.06)$ \\
\hline Mean provider cost (USD) (SD) & $372.83(0.06)$ & $361.65(0.03)$ & 4.95 \\
Life-years (LYs) gained & 5.21 & 5.05 & 3.27 \\
QALYs gained & 3.44 & 3.34 & $927.44(0.05)$ \\
\hline Genetic testing & & & 5.82 \\
\hline Mean provider cost (USD) (SD) & $976.26(0.05)$ & $946.97(0.05)$ & 4.72 \\
Life-years (LYs) gained & 6.13 & 5.95 & 5.82 \\
QALYs gained & 4.97 & $585.318(585.317-585.319)$ & $573.25(573.25-573.26)$ \\
Mean provider cost (USD) & $603.424(603.422-603.425)$ & & \\
difference (95\% CI) & & & \\
\hline
\end{tabular}

iFOBT: immunological-based fecal occult blood test; LYs: Life-Years; QALYs: Quality-Adjusted Life-Years; USD: United States Dollar; SD: standard deviation; CI: confidence interval. 


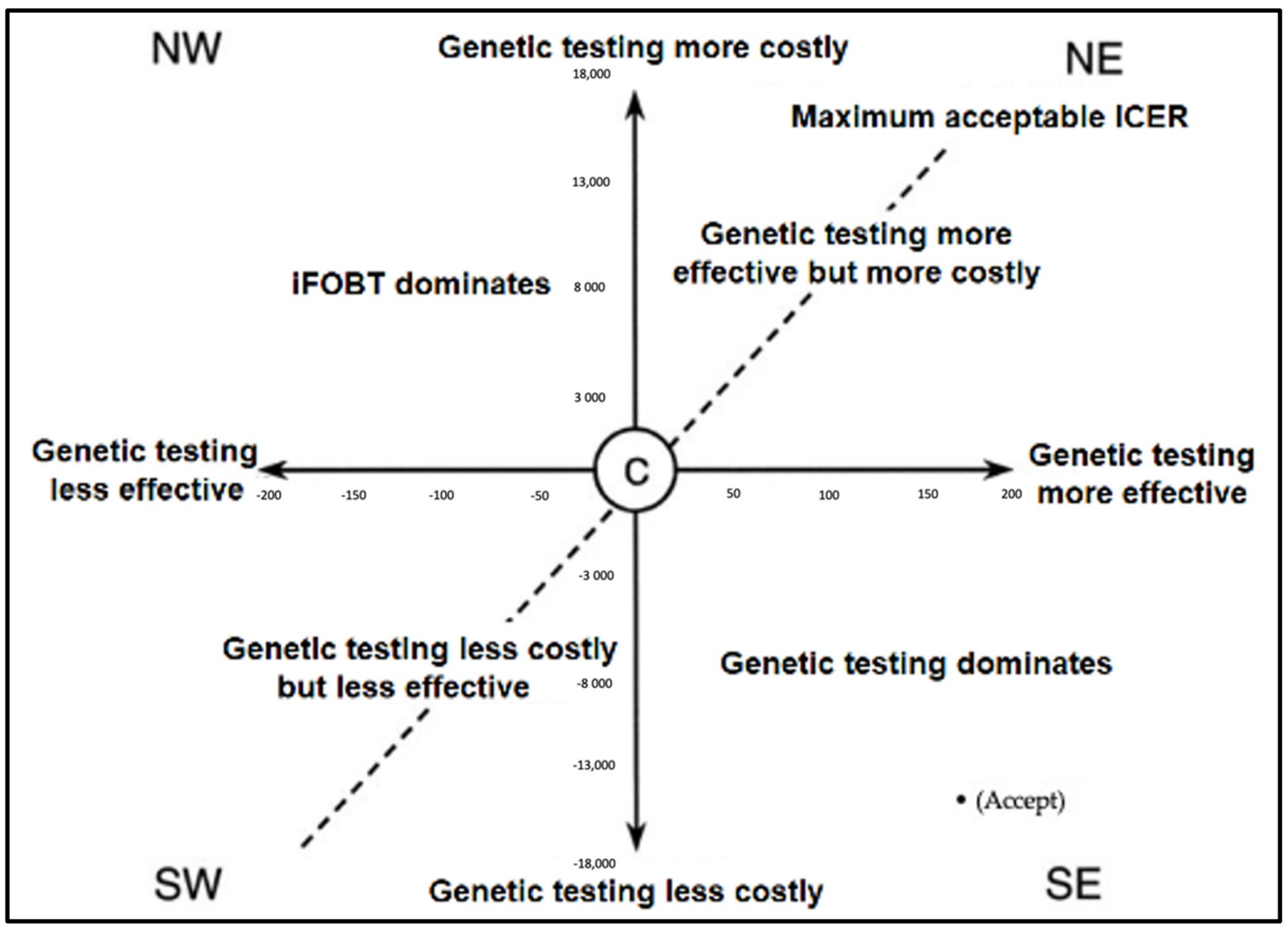

Figure 1. The cost-effectiveness plane and decision rules for CRC genetic testing compared to iFOBT. iFOBT: immunologicalbased fecal occult blood test; ICER: incremental cost-effectiveness ratio.

\section{Discussion}

The numbers of LYs and QALYs for patients undergoing screening through genetic testing were higher than those for patients undergoing screening through the iFOBT. The cost-effectiveness analysis in this study is presented through cost per LY and cost per QALY. The cost per LY (USD 160.04) for patients undergoing screening through genetic testing was found to be USD 88.48, higher than the cost per LY for patients undergoing screening through the iFOBT (USD 71.56). As for the cost per QALY (USD 217.92), the cost per QALY for patients undergoing screening through genetic testing was USD 126.76, higher than the cost per QALY for patients undergoing screening through the iFOBT (USD 91.16).

The incremental cost-effectiveness ratio (ICER) is the ratio of the increase in cost difference of the two screening methods to the increase in difference of the two effectiveness effects of this study. The lowest incremental cost-effectiveness ratio is the most cost-effective treatment option and is comparable to the value of the Gross Domestic Product (GDP) per capita $[65,66]$. This ratio is classified into one of three categories: either highly costeffective, cost-effective, or non-cost-effective. An ICER value of less than one GDP per capita is the most cost-effective choice of CRC screening method, while a value between two and three GDP per capita is considered cost-effective, and a value of more than three GDP per capita is considered ineffective [67,68]. A study by Lim et al. [69] to find the threshold point for Malaysia suggested that there is no single willingness-to-pay (WTP) value for quality-adjusted life-years [69]. The threshold for estimated cost-effectiveness for Malaysia was found to be lower than the threshold value recommended by the World Health Organization.

In this study, the ICER revealed that genetic testing dominates iFOBT testing. Therefore, $\mathrm{CRC}$ genetic testing is highly cost-effective when compared to iFOBT testing. These findings coincide with those of a study by Vasen et al. [51], who found that genetic test- 
ing was more cost-effective than no testing. Dinh et al. [48] also noted that individual screening for MMR gene mutations, beginning with risk assessment between the ages of 25 and 35 years, followed by genetic testing on individuals whose risk exceeds $5 \%$, is a cost-effective strategy as compared to iFOBT. In fact, cost-effectiveness analytical studies of genetic testing in Taiwan and Australia found genetic testing to be highly cost-effective as compared to no screening $[46,47,49,50]$. However, the use of genetic testing has been debated because of the increased costs in unnecessary monitoring and treatment that cause it to outweigh the benefits [70,71]. A study by Gallego et al. [72] on the cost-effectiveness of genetic testing for CRC diagnosis among patients referred to cancer genetics clinics showed that the use of hereditary CRC gene panel genetic testing is cost-effective with significant clinical benefits [72]. Most studies used the Markov model to obtain the ICER, but in this study, we compared the costs and results of interventions with similar goals at the group level rather than at the individual level. In reality, every health intervention should be carried out as a whole.

Several studies have used the Markov model to analyze the cost-effectiveness of CRC screening. A study by Wong et al. [73] found that adopting iFOBT annually is a cost-effective screening strategy compared to other recommended screening methods, depending on the willingness to pay for CRC screening among the Chinese population using the Markov model. That study compared the cost-effectiveness of a screening strategy proposed to a Chinese population of 50-year-olds over a 25-year period, namely, annual $\mathrm{gFOBT}$, annual iFOBT, and colonoscopy every 10 years. Data for each screening strategy according to the stage of $\mathrm{CRC}$ and cost data for each patient were taken from published studies. Quality-adjusted life-years (QALYs) were measured based on the stage duration and valued based on patient preferences using the SF-6D survey according to cancer stage. The cost-effectiveness result is the additional cost-effectiveness ratio (ICER), i.e., the cost per life-year (LY) and cost per QALY gained. Finally, Wong et al. [73] concluded that iFOBT annually is the most effective and cost-effective CRC screening strategy among the recommended screening strategies, depending on the willingness to pay for screening among the Chinese population [73].

A study in New Zealand using the Markov model also found that CRC screening using the iFOBT every two years was cost-effective. However, the risk of health inequality increased for the Māori population given that their willingness to pay was low [74]. Therefore, to prevent or reduce further health inequalities, attention should be given to disadvantaged population groups when planning and implementing screening programs. A study by Ladabaum et al. [75] also used a model to show that CRC screening initiated at the age of 45 is very cost-effective when compared to no screening or screening initiated at 50 years of age [75]. The use of the iFOBT was found to be more cost-effective, while the use of colonoscopy was more expensive. Although monitoring seemed expensive, it provided significant clinical and economic benefits, especially to those aged $\geq 65$ years [76]. The study by Ladabaum et al. (2011) found that genetic testing could reduce the number of deaths from CRC by $7-42 \%$ with an ICER of USD 36,200 per LY obtained [77].

Many studies have found that CRC screening modalities are cost-effective. The screening methods considered in these studies were iFOBT (70\%), colonoscopy $(67 \%)$, gFOBT $(42 \%)$, and sigmoidoscopy $(30 \%)$, but they were not conclusive on which screening method is the best to adopt for population-based CRC screening programs [78]. While the study by Jahn et al. [79] concluded that the most effective CRC screening method was iFOBT annually or colonoscopy every 10 years, the gFOBT was less effective and more expensive than the iFOBT. Colonoscopy was found to be cost-effective compared to no screening, and an ICER of 15,000 EUR per LY was obtained when colonoscopy was switched with the iFOBT [79]. A cost-benefit analysis study by Heavener et al. [80] also showed that CRC screening gives great returns; however, health systems need to construct payment models to provide better incentives to health providers who implement CRC screening [81]. Other studies have concluded that colonoscopy screening has the potential to become the most 
cost-effective form of CRC screening [82,83]. However, if the recipient prefers non-invasive testing, other screening strategies, such as genetic testing, could be considered.

\section{Study Strengths and Limitations}

There are some strengths and limitations to this study. In this study, we analyzed the cost-effectiveness of CRC genetic testing in Malaysia. To the best of our knowledge, this analysis is the first to see whether genetic testing is more cost-effective than the iFOBT. Therefore, these findings are able to provide an overview as a base for policy makers to expand the use of genetic testing nationally. We used the universal and frequently used EQ-5D-5L survey form to conduct a health economic assessment of a screening or treatment method. Therefore, the findings of this study can be compared with the results of studies conducted abroad. A study conducted by Huang et al. using EQ-5D-5L found that patients with early stages of CRC had better quality of life as compared to those with late stages of CRC [84]. We found that pain/discomfort was the most frequently reported problem amongst CRC patients. This finding was consistent with previous studies [85-87].

The limitations of this study need to be acknowledged. According to Drummond [62], cost analysis is a core element in health economics assessment studies. It needs to be done carefully and preferably from a community perspective. With this, economic evaluation studies will become more extensive and more relevant [81]. We only calculated cost analysis from the provider's perspective, particularly from that of the Ministry of Health. Because genetic testing has limited availability, being highly selective regarding patients and entirely subsidized by the government of Malaysia, the current study needs to consider the provider's perspective for economic evaluation of the tests available, and to account for deterministic and stochastic resource use and costs. Appraisal of the economic evaluation in the current study needs to be made with caution, as applying a "societal perspective", although preferred, will substantially impose a "spillover effect", as chronic diseases such as cancer at different stages will include caregiver costs and effects, and this does not fundamentally represent the cost burden to the principal provider in Malaysia, the government.

The study was conducted in three specialist hospitals serving as CRC referral centers. Generalization of the study findings cannot be made. The subjects of this study were only approached by the specialist referral hospitals; thus, the patients being recruited were mostly at an advanced stage of cancer. In Malaysia, the iFOBT and genetic testing are not performed as population-based screening tests for CRC. The iFOBT is only implemented as an opportunistic screening option where individuals attending healthcare facilities are offered the opportunity to undergo screening for CRC, while genetic testing is newly available and offered under limited capacity at a single selected tertiary specialist hospital (Kuala Lumpur Hospital) for high-risk target groups. This situation made patient recruitment to the current study difficult, as only few samples could be recruited during the study period. Being a cross-sectional study, all positive CRC patients at the time of study in those facilities were recruited, and their records were retrospectively examined to determine which test was used. As such, subject recruitment could not be expanded to the population level. Given its acceptable test performance, genetic testing has been adopted in the Malaysian Clinical Practice Guidelines for CRC screening and management; it is offered in selected tertiary specialist hospitals and entirely subsidized by the government of Malaysia. Hence, the provider is highly selective about which patients are assigned to undergo genetic testing. With such methodological, design, and resource implications, this paper is indeed directed, although not in its entirety, towards establishing the value of diagnostics and prognostics for new health technology assessments (HTAs). As crosssectional studies collect data (utility) at one point of time, CRC patients administered the questionnaire in the current study only responded once, at their particular stage of cancer, thus accruing stochastic uncertainties. Newer technologies differ in the way in which the value is accrued in the user populations, which is critically dependent on the value and availability of downstream healthcare choices [63]. Hence, linked-evidence approaches are 
the best opportunities for modelling associated with areas of policy, but this study was not powered to execute such modelling analytics; however, it could provide fundamental descriptive insight by incorporating complex information of dichotomous test variables with continuous measures (utilities) or multiple categories (cancer stages) for essential interpretations from the health economic perspective.

Data completeness is one of the limitations in this study. Secondary data obtained mainly from the Department of Finance and the Department of Medical Records were incomplete for analysis in this study. The lack of fully computerized systems in government hospitals, especially Kuala Lumpur Hospital, resulted in lower data availability. This problem was solved by face-to-face verification with the officers involved, and good explanations were obtained and comparable with trusted sources.

\section{Conclusions}

In conclusion, CRC genetic testing is cost-effective as compared to the iFOBT. This costeffectiveness analysis of CRC genetic testing provides important and valuable information for the government to consider genetic testing as a screening method to detect cases earlier and for further management to reduce complications, mortality, and economic burden related to CRC.

Author Contributions: Conceptualization, A.R.R., M.R.A.M., A.N.A., Z.A.L., K.W.T., G.-S.C. and S.M.A.; Data curation, Z.A.L., K.W.T. and G.-S.C.; Formal analysis, A.R.R., M.R.A.M., A.N.A., K.G. and S.M.A.; Investigation, A.R.R., M.R.A.M., A.N.A. and S.M.A.; Methodology, A.R.R., M.R.A.M., A.N.A., K.G. and S.M.A.; Project administration, A.R.R., M.R.A.M., A.N.A. and S.M.A.; Resources, Z.A.L., K.W.T. and G.-S.C.; Supervision, M.R.A.M., A.N.A. and S.M.A.; Validation, K.G.; Visualization, K.G.; Writing—original draft, A.R.R. and K.G.; Writing—review and editing, M.R.A.M., A.N.A. and S.M.A. All authors have read and agreed to the published version of the manuscript.

Funding: This study was part of the Long-Term Research Grant Scheme (LRGS/2014/UKMUKM/K/05); The Cancer Genome Atlas (TCGA): Molecular Networks for Improving Diagnosis and Treatment of Cancer (sub-group four entitled Knowledge, Attitude, Practices (KAP), Cost-Benefit and Psycho-Education of Cancer Genetic Testing Among Patients, Family and Community).

Institutional Review Board Statement: The study was conducted according to the guidelines of the Declaration of Helsinki and approved by the Ethics Committee of the Universiti Kebangsaan Malaysia (UKM) (approval number UKM PPI/111/8/JEP-2016-531) and the Medical Research Ethics Committee (MREC), National Medical Research Register (NMRR) of Malaysia (approval number NMRR-18-725-39826 (IIR)). The reporting of this economic evaluation followed the Consolidated Health Economic Evaluation Reporting Standards (CHEERS) statement.

Informed Consent Statement: Informed consent was obtained from all subjects involved in the study.

Data Availability Statement: The data presented in this study are available within the article.

Acknowledgments: The authors would like to thank all the enumerators for their cooperation during this study.

Conflicts of Interest: The authors declare no conflict of interest.

\section{References}

1. World Health Organization. Cancer Fact Sheets 2018. Available online: https://www.who.int/newsroom/fact-sheets/detail/ cancer (accessed on 1 January 2020).

2. Bray, F.; Ferlay, J.; Soerjomataram, I.; Siegel, R.L.; Torre, L.A.; Jemal, A. Global Cancer Statistics 2018: Globocan estimates of incidence and mortality worldwide for 36 cancers in 185 countries. CA Cancer J. Clin. 2018, 68, 394-424. [CrossRef]

3. Ferlay, J.; Colombet, M.; Soerjomataram, I.; Mathers, C.; Parkin, D.M.; Pineros, M.; Znaor, A.; Bray, F. Estimating the global cancer incidence and mortality in 2018: Globocan sources and methods. Int. J. Cancer 2019, 144, 1941-1953. [CrossRef] [PubMed]

4. Siegel, R.L.; Torre, L.A.; Soerjomataram, I.; Hayes, R.B.; Bray, F.; Weber, T.K.; Jemal, A. Global patterns and trends in colorectal cancer incidence in young adults. Gut 2019, 68, 2179-2185. [CrossRef] [PubMed]

5. Azizah, A.M.; Hashimah, B.; Nirmal, K.; Siti Zubaidah, A.R.; Puteri, N.A.; Nabihah, A.; Sukumaran, R.; Balqis, B.; Nadia, S.M.R.; Sharifah, S.S.S.; et al. Malaysia Cancer Statistics from the Malaysian National Cancer Registry Report 2012-2016; National Cancer Institute, Ministry of Health Malaysia: Putrajaya, Malaysia, 2019. 
6. Arnold, M.; Sierra, M.S.; Laversanne, M.; Soerjomataram, I.; Jemal, A.; Bray, F.I. Global patterns and trends in colorectal cancer incidence and mortality. Gut 2017, 66, 683-691. [CrossRef]

7. Brosens, L.A.; Offerhaus, G.J.A.; Giardiello, F.M. Hereditary colorectal cancer: Genetics and screening. Surg. Clin. N. Am. 2015, 95, 1067-1080. [CrossRef]

8. Lynch, H.T.; Shaw, T.G. Practical genetics of colorectal cancer. Chin. Clin. Oncol. 2013, 2, 12. [PubMed]

9. Gupta, S.; Provenzale, D.; Llor, X.; Halverson, A.L.; Grady, W.; Chung, D.C.; Haraldsdottir, S.; Markowitz, A.J.; Slavin, T.P., Jr.; Hampel, H.; et al. NCCN guidelines insights: Genetic/familial high-risk assessment: Colorectal, version 2.2019. J. Natl. Compr. Canc. Netw. 2019, 17, 1032-1041. [CrossRef]

10. Lorans, M.; Dow, E.; Macrae, F.A.; Winship, I.M.; Buchanan, D.D. Update on hereditary colorectal cancer: Improving the clinical utility of multigene panel testing. Clin. Colorectal Cancer 2018, 17, e293-e305. [CrossRef]

11. Prince, A.E.; Cadigan, R.J.; Henderson, G.E.; Evans, J.P.; Adams, M.; Coker-Schwimmer, E.; Penn, D.C.; Van Riper, M.; CorbieSmith, G.; Jonas, D.E. Is there evidence that we should screen the general population for Lynch syndrome with genetic testing? A systematic review. Pharmgenom. Pers. Med. 2017, 10, 49. [CrossRef]

12. Hamzehzadeh, L.; Yousefi, M.; Ghaffari, S.H. Colorectal cancer screening: A comprehensive review to recent non-invasive methods. Int. J. Hematol. Oncol. Stem Cell Res. 2017, 11, 250-261.

13. Carethers, J.M.; Jung, B.H. Genetics and genetic biomarkers in sporadic colorectal cancer. Gastroenterology 2015, 149, 1177-1190. [CrossRef]

14. Vasen, H.F.; Wijnen, J.T.; Menko, F.H.; Kleibeuker, J.H.; Taal, B.G.; Griffioen, G.; Nagengast, F.M.; Meijers-Heijboer, E.H.; Bertario, L.; Varesco, L.; et al. Cancer risk in families with hereditary nonpolyposis colorectal cancer diagnosed by mutation analysis. Gastroenterology 1996, 110, 1020-1027. [CrossRef] [PubMed]

15. Aaltonen, L.A.; Peltomaki, P.; Mecklin, J.P.; Jarvinen, H.; Jass, J.R.; Green, J.S.; Lynch, H.T.; Watson, P.; Tallqvist, G.; Juhola, M.J.C.R. Replication errors in benign and malignant tumors from hereditary nonpolyposis colorectal cancer patients. Cancer Res. 1994, 54, 1645-1648. [PubMed]

16. Miyaki, M.; Konishi, M.; Tanaka, K.; Kikuchi-Yanoshita, R.; Muraoka, M.; Yasuno, M.; Igari, T.; Koike, M.; Chiba, M.; Mori, T. Germline mutation of MSH6 as the cause of hereditary nonpolyposis colorectal cancer. Nat. Genet. 1997, 17, 271-272. [CrossRef]

17. Aarnio, M.; Sankila, R.; Pukkala, E.; Salovaara, R.; Aaltonen, L.A.; De La Chapelle, A.; Peltomaki, P.; Mecklin, J.P.; Jarvinen, H.J. Cancer risk in mutation carriers of DNA-mismatch-repair genes. Int. J. Cancer 1999, 81, 214-218. [CrossRef]

18. Giardiello, F.M.; Allen, J.I.; Axilbund, J.E.; Boland, C.R.; Burke, C.A.; Burt, R.W.; Church, J.M.; Dominitz, J.A.; Johnson, D.A.; Kaltenbach, T.; et al. Guidelines on genetic evaluation and management of Lynch syndrome: A consensus statement by the US multi-society task force on colorectal cancer. Gastroenterology 2014, 57, 1025-1048. [CrossRef]

19. Vasen, H.; Stormorken, A.; Menko, F.; Nagengast, F.; Kleibeuker, J.; Griffioen, G.; Taal, B.; Moller, P.; Wijnen, J.T. MSH2 mutation carriers are at higher risk of cancer than MLH1 mutation carriers: A study of hereditary nonpolyposis colorectal cancer families. J. Clin. Oncol. 2001, 19, 4074-4080. [CrossRef]

20. Rodriguez-Bigas, M.; Boland, C.; Hamilton, S.; Henson, D.; Jass, J.; Khan, P.; Lynch, H.; Perucho, M.; Smyrk, T.H.; Sobin, L.; et al. A National Cancer Institute workshop on hereditary nonpolyposis colorectal cancer syndrome: Meeting highlights and Bethesda guidelines. J. Natl. Cancer Inst. 1998, 89, 1758-1762. [CrossRef]

21. Umar, A.; Boland, C.R.; Terdiman, J.P.; Syngal, S.; Chapelle, A.D.L.; Ruschoff, J.; Fishel, R.; Lindor, N.M.; Burgart, L.J.; Hamelin, R.; et al. Revised Bethesda guidelines for hereditary nonpolyposis colorectal cancer (Lynch Syndrome) and microsatellite instability. J. Natl. Cancer Inst. 2004, 96, 261-268. [CrossRef]

22. Bonadona, V.; Bonaiti, B.; Olschwang, S.; Grandjouan, S.; Huiart, L.; Longy, M.; Guimbaud, R.; Buecher, B.; Bignon, Y.J.; Caron, O.; et al. French Cancer Genetics Network. Cancer risks associated with germline mutations in MLH1, MSH2, and MSH6 genes in Lynch Syndrome. JAMA 2011, 305, 2304-2310. [CrossRef]

23. Azzani, M.; Dahlui, M.; Ishak, W.Z.W.; Roslani, A.C.; Su, T.T. Provider costs of treating colorectal cancer in government hospital of Malaysia. Malays. J. Med. Sci. 2019, 26, 73. [CrossRef] [PubMed]

24. Azzani, M.; Roslani, A.C.; Su, T.T. Financial burden of colorectal cancer treatment among patients and their families in a middle-income country. Support Care Cancer 2016, 24, 4423-4432. [CrossRef]

25. Azzani, M.; Yahya, A.; Roslani, A.C.; Su, T.T. Catastrophic health expenditure among colorectal cancer patients and families: A case of Malaysia. Asia Pac. J. Public Health 2017, 29, 485-494. [CrossRef]

26. Mohd, N.; Ezat, S.; Aljunid, S.M.; Manaf, M.R.A.; Sulong, S.; Sagap, I.; Azrif, M. Cost analysis of colorectal cancer (CRC) management in UKM Medical Centre using Clinical Pathway. BMC Public Health 2012, 12, A40. [CrossRef]

27. Ezat, S.; Natrah, M.; Aljunid, S.; Rizal, M.; Saperi, S.; Ismail, S.; Fuad, I.; Azrif, M.A. Economic evaluation of monoclonal antibody in the management of colorectal cancer. J. Cancer Res. Ther. 2013, 1, 34-39.

28. Shah, S.A.; Neoh, H.M.; Rahim, S.; Azhar, Z.I.; Hassan, M.R.; Safian, N.; Jamal, R.J. Spatial analysis of colorectal cancer cases in Kuala Lumpur. Asian Pac. J. Cancer Prev. 2014, 15, 1149-1154. [CrossRef]

29. Veettil, S.K.; Lim, K.G.; Chaiyakunapruk, N.; Ching, S.M.; Hassan, M.R.A. Colorectal cancer in Malaysia: Its burden and implications for a multiethnic country. Asian J. Surg. 2017, 40, 481-489. [CrossRef]

30. Beaulieu, N.; Bloom, D.; Bloom, R.; Breakaway, S. The Global Burden of Cancer-Challenges and Opportunities. A Report from the Economist Intelligent Unit; The Economist Intelligence Unit: Singapore, 2009. 
31. Bhoo-Pathy, N.; Ng, C.W.; Lim, G.C.C.; Tamin, N.S.I.; Sullivan, R.; Bhoo-Pathy, N.T.; Abdullah, M.M.; Kimman, M.; Subramaniam, S.; Saad, M.; et al. Financial toxicity after cancer in a setting with universal health coverage: A call for urgent action. J. Oncol. Pract. 2019, 15, e537-e546. [CrossRef]

32. Favoriti, P.; Carbone, G.; Greco, M.; Pirozzi, F.; Pirozzi, R.E.M.; Corcione, F. Worldwide burden of colorectal cancer: A review. Updates Surg. 2016, 68, 7-11. [CrossRef]

33. Subramanian, S.; Tangka, F.K.L.; Hoover, S.; Royalty, J.; Degroff, A.; Joseph, D. Costs of colorectal cancer screening provision in CDC's colorectal cancer control program: Comparisons of colonoscopy and FOBT/FIT based screening. Eval. Program Plann. 2017, 62, 73-80. [CrossRef] [PubMed]

34. Prager, G.W.; Braga, S.; Bystricky, B.; Qvortrup, C.; Criscitiello, C.; Esin, E.; Sonke, G.S.; Martinez, G.A.; Frenel, J.S.; Karamouzis, M.; et al. Global cancer control: Responding to the growing burden, rising costs and inequalities in access. ESMO Open 2018, 3, e000285. [CrossRef]

35. Yabroff, K.R.; Borowski, L.; Lipscomb, J. Economic studies in colorectal cancer: Challenges in measuring and comparing costs. JNCI Monogr. 2013, 46, 62-78. [CrossRef]

36. American Cancer Society. Colorectal Cancer 2017. Available online: https://www.cancer.org/cancer/colon-rectal-cancer/about/ key-statistics.html (accessed on 2 December 2018).

37. Andersen, S.W.; Blot, W.J.; Lipworth, L.; Steinwandel, M.; Murff, H.J.; Zheng, W. Association of race and socioeconomic status with colorectal cancer screening, colorectal cancer risk, and mortality in Southern US adults. JAMA Netw. Open 2019, 2, e1917995. [CrossRef]

38. Bibbins-Domingo, K.; Grossman, D.C.; Curry, S.J.; Davidson, K.W.; Epling, J.W.; Garcia, F.A.; Gillman, M.W.; Harper, D.M.; Kemper, A.R.; Krist, A.H.; et al. Screening for colorectal cancer: US preventive services task force recommendation statement. JAMA 2016, 315, 2564-2575.

39. Schreuders, E.H.; Ruco, A.; Rabeneck, L.; Schoen, R.E.; Sung, J.J.; Young, G.P.; Kuipers, E.J. Colorectal cancer screening: A global overview of existing programmes. Gut 2015, 64, 1637-1649. [CrossRef]

40. Sung, J.J.; Ng, S.C.; Chan, F.K.; Chiu, H.M.; Kim, H.S.; Matsuda, T.; Ng, S.S.; Lau, J.Y.; Zheng, S.; Adler, S.; et al. An updated Asia Pacific Consensus Recommendations on Colorectal Cancer Screening. Gut 2015, 64, 121-132. [CrossRef]

41. Swartz, A.W.; Eberth, J.M.; Josey, M.J.; Strayer, S.M. Reanalysis of all-cause mortality in the US Preventive Services Task Force 2016 Evidence Report on Colorectal Cancer Screening. Ann. Intern. Med. 2017, 167, 602-603. [CrossRef]

42. Ministry of Health Malaysia. Guidelines for Screening Programs of Colorectal Cancer (Cancer of the Big Bowel); Ministry of Health Malaysia: Putrajaya, Malaysia, 2015.

43. Ministry of Health Malaysia. Clinical Practice Guidelines: Management of Colorectal Cancer Malaysia Health Technology Assessment Section (MaHTAS); Ministry of Health Malaysia: Putrajaya, Malaysia, 2017.

44. Al-Dubai, S.A.; Ganasegeran, K.; Alabsi, A.M.; Shah, S.A.; Razali, F.M.M.; Arokiasamy, J.T. Exploration of risk-taking behaviors and perceived susceptibility of colorectal cancer among Malaysian adults: A community based cross-sectional study. BMC Public Health 2013, 13, 930. [CrossRef]

45. Payne, K.; Gavan, S.P.; Wright, S.J.; Thompson, A.J. Cost-effectiveness analyses of genetic and genomic diagnostic tests. Nat. Rev. Genet. 2018, 19, 235-246. [CrossRef]

46. Cenin, D.R.; Naber, S.K.; Lansdorp-Vogelaar, I.; Jenkins, M.A.; Buchanan, D.D.; Preen, D.B.; Ee, H.C.; O’Leary, P. Costs and outcomes of Lynch syndrome screening in the Australian colorectal cancer population. J. Gastroenterol. Hepatol. 2018, 33, 1737-1744. [CrossRef]

47. Chen, Y.E.; Kao, S.S.; Chung, R.H. Cost-effectiveness analysis of different genetic testing strategies for Lynch syndrome in Taiwan. PLoS ONE 2016, 11, e0160599. [CrossRef]

48. Dinh, T.A.; Rosner, B.I.; Atwood, J.C.; Boland, C.R.; Syngal, S.; Vasen, H.F.; Gruber, S.B.; Burt, R.W. Health benefits and costeffectiveness of primary genetic screening for Lynch syndrome in the general population. Cancer Prev. Res. 2011, 4, 9-22. [CrossRef]

49. Grosse, S.D. When is genomic testing cost-effective? Testing for Lynch syndrome in patients with newly-diagnosed colorectal cancer and their relatives. Healthcare 2015, 3, 860-878. [CrossRef]

50. Kang, Y.J.; Killen, J.; Caruana, M.; Simms, K.; Taylor, N.; Frayling, I.M.; Snowsill, T.; Huxley, N.; Coupe, V.M.; Hughes, S.; et al. The predicted impact and cost-effectiveness of systematic testing of people with incident colorectal cancer for Lynch syndrome. Med. J. Aust. 2020, 212, 72-81. [CrossRef]

51. Vasen, H.F.; Ballegooijen, M.V.; Buskens, E.; Kleibeuker, J.K.; Taal, B.G.; Griffioen, G.; Nagengast, F.M.; Menko, F.H.; Khan, P.M. A cost-effectiveness analysis of colorectal screening for hereditary nonpolyposis colorectal carcinoma gene carriers. Cancer 1998, 82, 1632-1637. [CrossRef]

52. Brazier, J.; Ratcliffe, J.; Saloman, J.; Tsuchiya, A. Measuring and Valuing Health Benefits for Economic Evaluation, 2nd ed.; Oxford University Press: Oxford, UK, 2017.

53. Rabin, R.; de Charro, F. EQ-5D: A measure of health status from the EuroQol Group. Ann. Med. 2001, 33, 337-343. [CrossRef]

54. Arifin, B.; Purba, F.D.; Herman, H.; Adam, J.M.; Atthobari, J.; Schuiling-Veninga, C.C.; Krabbe, P.F.M.; Postma, M.J. Comparing the EQ-5D-3L and EQ-5D-5L: Studying measurement and scores in Indonesian type 2 diabetes mellitus patients. Health Qual. Life Outcomes 2020, 18, 22. [CrossRef] [PubMed] 
55. Shafie, A.A.; Thakumar, A.V.; Lim, C.J.; Luo, N.; Rand-Hendriksen, K.; Yusof, F.A.M. EQ-5D-5L valuation for the Malaysian population. Pharmacoeconomics 2019, 37, 715-725. [CrossRef]

56. Yusof, F.A.; Goh, A.; Azmi, S. Estimating an EQ-5D value set for Malaysia using time trade-off and visual analogue scale methods. Value Health 2012, 15, S85-S90. [CrossRef]

57. Van Reenen, M.; Janssen, B. EQ-5D-5L User Guide: Basic Information on How to Use the EQ-5D-5L Instrument; EuroQol Research Foundation: Rotterdam, The Netherlands, 2015.

58. National Cancer Registry Ministry of Health Malaysia. Malaysian Study on Cancer Survival (Myscan); NCSM: Putrajaya, Malaysia, 2018.

59. Lee, K.Y.; Ong, T.K.; Low, E.V.; Liow, S.Y.; Anchah, L.; Hamzah, S.; Liew, H.B.; Ali, R.M.; Ismail, O.; Ahmad, W.A.W.; et al. Cost of elective percutaneous coronary intervention in Malaysia: A multi-centre cross-sectional costing study. BMJ Open 2017, 7, e014307. [CrossRef]

60. Mohd Dom, T.N.; Ayob, R.; Abd Muttalib, K.; Aljunid, S.M. National Economic Burden Associated with Management of Periodontitis in Malaysia. Int. J. Dent. 2016, 2016, 1891074. [CrossRef] [PubMed]

61. Creese, A.; Parker, D. Cost Analysis in Primary Health Care. A Training Manual for Program Managers; WHO Publications Center: Albany, NY, USA, 1994.

62. Drummond, M.F.; Sculpher, M.J.; Claxton, K.; Stoddart, G.L.; Torrance, G.W. Methods for the Economic Evaluation of Health Care Programmes; Oxford University Press: Oxford, UK, 2015.

63. Soares, M.O.; Walker, S.; Palmer, S.J.; Sculpher, M.J. Establishing the value of diagnostic and prognostic tests in health technology assessment. Med. Decis. Making 2018, 38, 495-508. [CrossRef]

64. Ramdzan, A.R.; Abd Rahim, M.A.; Mohamad Zaki, A.; Zaidun, Z.; Mohammed Nawi, A. Diagnostic accuracy of FOBT and colorectal cancer genetic testing: A systematic review \& meta-analysis. Ann. Glob. Health 2019, 85, 70.

65. Malaysia Health Technology Assessment Section. Establishing a Cost Effectiveness Threshold Value for Health Technologies. 2015. Available online: https: / $/$ www.google.com.hk/url?sa=t\&rct=j\&q=\&esrc=s\&source=web\&cd=\&cad=rja\&uact=8\&ved= 2ahUKEwj72dyg-pvyAhXQ1GEKHXYrD-MQFnoECAUQAw\&url=https\%3A\%2F\%2Fwww.moh.gov.my\%2Findex.php\% 2Ffile_manager\%2Fdl_item\%2F54574649564546544945356c64334e735a5852305a5849764d6c394e5955685551564e66546d5633633 2786c6448526c636c3957623278664d5463756347526d\&usg=AOvVaw3nD4VWGJ7Bekf9zAT3G8ym (accessed on 1 December 2020).

66. Marseille, E.; Larson, B.; Kazi, D.S.; Kahn, J.G.; Rosen, S. Thresholds for the cost-effectiveness of interventions: Alternative approaches. Bull. World Health Organ. 2015, 93, 118-124. [CrossRef]

67. Grosse, S.D. Assessing cost-effectiveness in healthcare: History of the $\$ 50,000$ per qaly threshold. Expert Rev. Pharmacoecon. Outcomes Res 2008, 8, 165-178. [CrossRef]

68. Tan-Torres Edejer, T.; Baltussen, R.; Adam, T.; Hutubessy, R.; Acharya, A.; Evans, D.B.; Murray, C.J. Making Choices in Health: WHO Guide to CostEffectiveness Analysis; World Health Organization: Geneva, Switzerland, 2003.

69. Lim, Y.W.; Shafie, A.A.; Chua, G.N.; Hassali, M.A.A. Determination of cost-effectiveness threshold for health care interventions in Malaysia. Value Health 2017, 20, 1131-1138. [CrossRef]

70. Bombard, Y.; Bach, P.B.; Offit, K. Translating genomics in cancer care. J. Natl. Compr. Canc. Netw. 2013, 11, 1343-1353. [CrossRef]

71. Ngeow, J.; Heald, B.; Rybicki, L.A.; Orloff, M.S.; Chen, J.L.; Liu, X.; Yerian, L.; Willis, J.; Lehtonen, H.J.; Lehtonen, R.J.G. Prevalence of germline PTEN, BMPR1A, SMAD4, STK11, and ENG mutations in patients with moderate-load colorectal polyps. Gastroenterology 2013, 144, 1402-1409. [CrossRef]

72. Gallego, C.J.; Shirts, B.H.; Bennette, C.S.; Guzauskas, G.; Amendola, L.M.; Horike-Pyne, M.; Hisama, F.M.; Pritchard, C.C.; Grady, W.M.; Burke, W.; et al. Next generation sequencing panels for the diagnosis of colorectal cancer and polyposis syndromes: A cost-effectiveness analysis. J. Clin. Oncol. 2015, 33, 2084-2091. [CrossRef]

73. Wong, C.K.; Lam, C.L.; Wan, Y.F.; Fong, D.Y. Cost-effectiveness simulation and analysis of colorectal cancer screening in Hong Kong Chinese population: Comparison amongst colonoscopy, guaiac and immunologic fecal occult blood testing. BMC Cancer 2015, 15, 705. [CrossRef]

74. Mcleod, M.; Kvizhinadze, G.; Boyd, M.; Barendregt, J.; Sarfati, D.; Wilson, N.; Blakely, T. Colorectal cancer screening: How health gains and cost-effectiveness vary by ethnic group, the impact on health inequalities, and the optimal age range to screen. Cancer Epidemiol. Biomarkers Prev. 2017, 26, 1391-1400. [CrossRef]

75. Ladabaum, U.; Mannalithara, A.; Meester, R.G.; Gupta, S.; Schoen, R.E. Cost-effectiveness and national effects of initiating colorectal cancer screening for average-risk persons at age 45 years instead of 50 years. Gastroenterology 2019, 157, 137-148. [CrossRef]

76. Ladabaum, U.; Mannalithara, A.; Brill, J.V.; Levin, Z.; Bundorf, K.M. Contrasting effectiveness and cost-effectiveness of colorectal cancer screening under commercial insurance vs medicare. Am. J. Gastroenterol. 2018, 113, 1836-1847. [CrossRef]

77. Ladabaum, U.; Wang, G.; Terdiman, J.; Blanco, A.; Kuppermann, M.; Boland, C.R.; Ford, J.; Elkin, E.; Phillips, K.A. Strategies to identify the Lynch syndrome among patients with colorectal cancer: A cost-effectiveness analysis. Ann. Intern. Med. 2011, 155, 69-79. [CrossRef]

78. Mendivil, J.; Appierto, M.; Aceituno, S.; Comas, M.; Rue, M. Economic evaluations of screening strategies for the early detection of colorectal cancer in the average-risk population: A systematic literature review. PLoS ONE 2019, 14, e0227251. [CrossRef]

79. Jahn, B.; Sroczynski, G.; Bundo, M.; Muhlberger, N.; Puntscher, S.; Todorovic, J.; Rochau, U.; Oberaigner, W.; Koffijberg, H.; Fischer, T.; et al. Effectiveness, benefit, harm and cost effectiveness of colorectal cancer screening in Austria. BMC Gastroenterol. 2019, 19, 209. [CrossRef] 
80. Heavener, T.; Mcstay, F.W.; Jaeger, V.; Stephenson, K.; Sager, L.; Sing, J. Assessing adherence and cost-benefit of colorectal cancer screening for accountable providers. Proc. (Bayl. Univ. Med. Cent.) 2019, 32, 490-497. [CrossRef]

81. Jo, C. Cost-of-illness studies: Concepts, scopes, and methods. Clin. Mol. Hepatol. 2014, 20, 327. [CrossRef]

82. Sekiguchi, M.; Igarashi, A.; Sakamoto, T.; Saito, Y.; Esaki, M.; Matsuda, T. Cost-effectiveness analysis of colorectal cancer screening using colonoscopy, fecal immunochemical test, and risk score. J. Gastroenterol. Hepatol. 2020, 35, 1555-1561. [CrossRef]

83. Peterse, E.F.; Meester, R.G.; de Jonge, L.; Omidvari, A.H.; Alarid-Escudero, F.; Knudsen, A.B.; Zauber, A.G.; Lansdorp-Vogelaar, I. Comparing the cost-effectiveness of innovative colorectal cancer screening tests. J. Natl. Cancer Inst. 2021, 113, 154-161. [CrossRef]

84. Huang, W.; Yang, J.; Liu, Y.; Liu, C.; Zhang, X.; Fu, W.; Shi, L.; Liu, G. Assessing health-related quality of life of patients with colorectal cancer using EQ-5D-5L: A cross-sectional study in Heilongjiang of China. BMJ Open 2018, 8, e022711. [CrossRef] [PubMed]

85. Farkkila, N.; Torvinen, S.; Roine, R.P.; Sintonen, H.; Hanninen, J.; Taari, K.; Saarto, T. Health-related quality of life among breast, prostate, and colorectal cancer patients with end-stage disease. Qual. Life Res. 2014, 23, 1387-1394. [CrossRef]

86. Downing, A.; Morris, E.J.; Richards, M.; Corner, J.; Wright, P.; Sebag-Montefiore, D.; Finan, P.; Kind, P.; Wood, C.; Lawton, S.; et al. Health-related quality of life after colorectal cancer in England: A patient-reported outcomes study of individuals 12 to 36 months after diagnosis. J. Clin Oncol. 2015, 33, 616-624. [CrossRef] [PubMed]

87. Stein, D.; Joulain, F.; Naoshy, S.; Iqbal, U.; Muszbek, N.; Payne, K.A.; Ferry, D.; Goey, S.H. Assessing health-state utility values in patients with metastatic colorectal cancer: A utility study in the United Kingdom and the Netherlands. Int. J. Colorectal Dis. 2014, 29, 1203-1210. [CrossRef] [PubMed] 